\title{
VERTALERS EN TOLKEN MET VISUELE BEPERKING SPECIFIEKE PROBLEMEN EN MOGELIJKE OPLOSSINGEN
}

\author{
MICHAL HOMOLA
}

\begin{abstract}
Visual impaired translators and interpreters: specific problems and possible solutions

Visually impaired translators and interpreters have to cope with various specific problems in their work. The progress of modern technology has simplified access to information sources for them, but has in contrast created new barriers, which make their position on the market with translation and interpretation services more complicated.

My master's thesis analysed the problems of visually impaired translators and interpreters, especially on the basis of their own experience. I drew up a questionnaire, which was filled in by blind and partially sighted translators and interpreters from throughout the world. I would like to introduce the results of my research in this article. I would additionally like to map out the situation in the Dutch language area and compare it to the global outcomes. I found several visually impaired translators and interpreters from the Netherlands and Flanders and asked them to fill in an extended questionnaire. The number of respondents was not high enough to draw general conclusions, but it was nevertheless possible to observe certain parallels or differences.
\end{abstract}

Key words: visual impairment; interpreting; translating; assistive technology; CAT-tools

\section{Inleiding}

Mensen met visuele beperking hadden lange tijd slechts beperkte mogelijkheden op de arbeidsmarkt. Zij konden vaak alleen handmatig werk verrichten en kregen geen mogelijkheid om aan een universiteit te studeren. De echte mijlpaal voor hun integratie op de arbeidsmarkt was de opkomst van moderne technologieën aan het einde van de 20 -ste eeuw. Tegenwoordig kunnen mensen met een visuele beperking naast hun ziende leeftijdsgenoten studeren en zij vinden werk op verschillende gebieden van het maatschappelijke leven. Tot zulke gebieden horen ook vertalen en tolken. Wij kunnen vele voorbeelden van blinde of slechtziende vertalers en tolken in Europa maar ook elders in de 
wereld vinden die succesvol zijn. Zij werken voor EU- of overheidsinstellingen, doceren aan universiteiten of zijn actief als beëdigd vertalers en tolken. Desondanks worden zij bij hun studie en vooral bij hun werk met specifieke problemen geconfronteerd. Het is vaak moeilijk om deze problemen op te lossen. Maar nog erger is het feit dat zij vaak niet weten welke mogelijkheden er voor hen bestaan. Het is nodig dat zij al tijdens hun studie meer informatie krijgen, of misschien al voor de studie, die hen bij het zoeken naar effectieve oplossingen kan helpen. Daarom is het essentieel om deze problematiek te onderzoeken en mogelijke oplossingen van hun problemen te analyseren en te presenteren.

\section{Methodes en bronnen}

Wij hebben een onderzoek onder blinde en slechtziende vertalers en tolken in Nederland en Vlaanderen gedaan door middel van een vragenlijst. De vragenlijst bestond uit vragen die gericht zijn op persoonlijke ervaring van de vertalers en tolken. Onze respondenten hebben aangegeven met welke problemen zij bij hun werk worden geconfronteerd en welke oplossingen zij op basis van hun eigen ervaring voorstellen. Daarna probeerden wij deze ervaringen samen te vatten.

Wij gingen tevens van eerder onderzoek uit dat wij in het kader van onze masterscriptie hebben uitgevoerd. Het gaat opnieuw om een vragenlijst die door 16 vertalers en tolken met visuele beperking uit verschillende landen werd ingevuld (Homola 2017).

Bovendien gingen wij van meerdere praktische materialen uit die voor blinde en slechtziende vertalers en tolken beschikbaar zijn. Daaronder vallen wetenschappelijke studies en masterscripties, artikelen geschreven niet alleen door vertalers en tolken met visuele beperking, maar ook door docenten die persoonlijke ervaring met blinde of slechtziende studenten hebben. Wij hebben ons onderzoek dus enerzijds met empirische gegevens en anderzijds met theoretische analyses onderbouwd.

Er bestaan desondanks relatief weinig publicaties of studies die op deze problematiek ingaan. Er wordt vooral onderzoek op dit gebied gedaan aan universiteiten, waar blinde of slechtziende studenten studeren of hebben gestudeerd (Trieste, Germersheim, Warschau). In het Nederlandstalige gebied werden tot nu toe, voor zover wij weten, geen studies over deze problematiek gepubliceerd.

\section{Compensatie van visuele beperking}

Om specifieke problemen van blinde en slechtziende vertalers en tolken te kunnen begrijpen en mogelijke oplossingen te presenteren, is het noodzakelijk om een basiskennis van beschikbare hulpmiddelen te hebben waarmee de visuele beperking gecompenseerd kan worden. Daarom voegen we in deze paragraaf een overzicht van de belangrijkste hulptechnologieën toe.

De beperking van perceptie van informatie uit visuele bronnen moet door speciale methodes en hulpmiddelen worden gecompenseerd. Het is al lang niet meer zo dat mensen met een visuele beperking alleen op het brailleschrift aangewezen zouden zijn. De moderne technologieën maken het ook voor mensen met visuele beperkingen mogelijk 
om allerhande elektronische hulpmiddelen te gebruiken. Daardoor hebben zij toegang gekregen tot een enorme hoeveelheid informatie. Zij kunnen tegenwoordig dus werk verrichten dat voor hen in het verleden ontoegankelijk was.

Blinde en slechtziende mensen kunnen dankzij de vooruitgang met behulp van speciale software en hardware op efficiënte wijze met gewone computers omgaan. Als cruciaal kan zeker de zogenaamde schermleessoftware worden beschouwd. Het is een software die op de achtergrond van het besturingssysteem werkt. Zijn primaire functie is te bemiddelen tussen datgene wat op het scherm gebeurt en de gebruiker. Deze communiceert met de computer via het toetsenbord (blinde mensen gebruiken geen muis) en, omgekeerd, de computer communiceert met de gebruiker via de schermleessoftware die hem informatie ter beschikking stelt (Mendelová 2013). Het gebruik van schermleessoftware heeft echter ook nadelen met zich meegebracht. Vooral blinde gebruikers krijgen de informatie enkel in akoestische vorm. Daardoor verliezen zij hun woordbeeld. Om dit probleem op te lossen, werden er brailleleesregels ontwikkeld. Op de brailleleesregel kunt u teksten invoeren en lezen. Een brailleleesregel kan met een kabeltje, maar ook draadloos via bluetooth op een computer of smartphone aangesloten worden. Deze regels beschikken soms over een intern geheugen, waarop u tekst kunt opslaan om onderweg te lezen.

Met een schermlezer of brailleleesregel kan ook een blinde persoon documenten lezen en bewerken, op internet surfen, bestanden beheren en vele andere functies van zijn computer bedienen. Er bestaat echter nog steeds software die voor deze hulptechnologieën slechts gedeeltelijk toegankelijk of zelfs volledig ontoegankelijk is. Het werk met dergelijke software is voor blinde gebruikers daarom zeer problematisch.

\section{Toegankelijkheid van de CAT-tools}

Bij het werk van moderne vertalers worden steeds meer computertechnologieën gebruikt die de mogelijkheid bieden van het geautomatiseerd vertalen van elektronische documenten. Het moderne tijdperk stelt vooral hoge eisen aan de efficiëntie van processen op elk gebied van menselijke activiteit. Dat geldt ook voor het vertaalproces. De mogelijkheden van de mens worden echter door objectieve factoren beperkt en daarom worden ook op dit gebied met grote regelmaat nieuwe computertechnologieën ingevoerd, de zogenaamde Computer-Assisted Translation tools (CAT-tools). Deze bieden verschillende gereedschappen die het vertaalproces kunnen vereenvoudigen. Tot de belangrijkste ervan horen zeker terminologische databanken en vertaalgeheugens. Deze stellen de vertaler in staat tegelijkertijd met de brontekst en de doeltekst te werken (Craciunescu 2004).

CAT-tools worden vooral door vertaalbureaus gebruikt. Het gebruik van vertaalgeheugens is ook handig bij projecten waaraan meerdere vertalers tegelijkertijd werken. CAT-tools zorgen ook hier voor consequent taalgebruik en dragen eraan bij dat termen op een coherente manier vertaald worden.

Tegenwoordig is de snelheid van het vertaalproces een van de belangrijkste criteria bij het kiezen door de opdrachtgever van een vertaalbureau. Om hun concurrentiepositie te verhogen, proberen vertaalbureaus, maar ook freelancers, de modernste technologieën te gebruiken. Een goede kennis van het werk met CAT-tools is daarom zeker een van de belangrijkste eisen die door vertaalbureaus aan vertalers worden gesteld. Enerzijds 
is het positief nieuws voor blinde en slechtziende vertalers dat het vertaalproces steeds meer via computertechnologieën verloopt en dat daarmee het probleem van de digitalisering van teksten in papiervorm afgebouwd wordt. Anderzijds ontstaat hier een probleem van toegankelijkheid van CAT-tools voor schermleessoftware. Dat is een relatief nieuw probleem dat tot nu toe niet of nauwelijks is onderzocht. Kijken we naar SDL Trados Studio, waarschijnlijk een van de meest gebruikte CAT-tool in Europa. Deze software wordt door het bedrijf SDL ontwikkeld. Bij SDL Trados Studio is zoals bij de meeste CATs de toegankelijkheid van de gebruikersomgeving voor de schermlezers heel problematisch. Bij oudere versies (Trados 2007 en Trados 7) was dit probleem niet zo opvallend omdat deze versies een mogelijkheid boden om in Microsoft Word via Trados toolbar te werken. De toolbar bevatte verschillende opties voor de vertaler en was voor de schermlezer volledig toegankelijk, hoewel er ook functies waren die voor blinde vertalers niet toegankelijk waren. Met de versie 2009 werd Trados Studio voor blinde vertalers minder toegankelijk. Het was niet meer mogelijk om in Ms Word te werken. Daarom werden ook blinde gebruikers gedwongen de Trados interface te gebruiken. Deze interface is voor schermlezers minder toegankelijk dan de Ms Word interface. Bepaalde functionaliteiten blijven voor blinde gebruikers volledig ontoegankelijk. Het onderzoek van Rodríguez Vázquez \& Mileto (2016) heeft bovendien aangetoond dat het blinde vertalers heel veel moeite kost om alle toetsencombinaties te onthouden. Ziende vertalers kunnen vele van de functies met de muis bedienen, maar dat is voor gebruikers met visuele beperking moeilijk. De toegankelijkheid van Trados Studio is met de versies 2011 en 2014 niet verbeterd. Er bestaan toetsenbordcommando's waarmee het mogelijk zou zijn om zich tussen de verschillende gebieden van het navigatiemenu te bewegen. Het is echter niet mogelijk om vast te stellen waar zich de cursor bevindt (bron- of doelsegment). Enkele gegevens worden alleen als een symbool, grafisch teken of door middel van verandering van kleur getoond, wat voor blinde gebruikers helemaal niet leesbaar is. Deze uitkomsten gelden zowel voor de versie 2011 als voor die van 2014. Wij kunnen dus zonder twijfel concluderen dat de visuele presentatie van de interface voor de ontwikkelaars veel belangrijker bleef dan de toegankelijkheid voor blinde gebruikers. Recent werd ook de versie Trados Studio 2017 gelanceerd, maar naar deze werd nog geen grondig onderzoek gedaan.

Problemen met toegankelijkheid voor blinde en slechtziende vertalers werden ook bij andere CAT-tools ontdekt, zoals MemoQ, Acrossx of STAR Transit. De interface van deze tools is gedeeltelijk of volledig ontoegankelijk voor de populaire schermleessoftwares. Dat maakt het werk ermee voor blinde gebruikers heel moeilijk of helemaal onmogelijk.

Waarschijnlijk de meest toegankelijke CAT-tool voor blinde vertalers is FluencyNow, geproduceerd door Western Standard. Deze CAT-tool is in Europa zeker niet zo bekend en uitgebreid als bijvoorbeeld Trados Studio. Oorspronkelijk was ook Fluency ontoegankelijk voor blinde gebruikers. De ontwikkelaars waren echter bereid om met blinde en slechtziende mensen samen te werken en zij zijn aan hun toegankelijkheidswensen tegemoetgekomen. Niet alle functies zijn volledig toegankelijk, maar over het algemeen is deze CAT-tool voor vertalers met een visuele beperking bruikbaar.

Er bestaat nog een relatief breed scala aan onderwerpen met betrekking tot de interactie tussen CAT-tools en schermlezersgebruikers dat grondig onderzocht moet worden. De communicatie met de producenten van CATs kan hierbij een cruciale rol spelen. 


\section{Notitietechniek in het tolkproces}

Tot nu toe hebben wij ons met de toegankelijkheid van CAT-tools voor vertalers met visuele beperking beziggehouden. Nu richten wij onze aandacht op de problematiek van het tolkproces. Wij kunnen het proces van consecutief tolken in drie fasen verdelen:
a. begrijpen
b. analyseren
c. reproduceren/herformuleren (Jones 2002)

De derde fase van het proces van het consecutief tolken speelt voor blinde tolken een cruciale rol en kan voor hen heel problematisch zijn. Bij deze fase is het belangrijk om de inhoud van de oorspronkelijke tekst te herformuleren en aan de recipiënt over te dragen. Deze fase hangt nauw met de analyse van de relaties tussen concrete onderdelen en feiten in de originele tekst samen. Als de tolk namelijk aan de hand van zijn aantekeningen een goede analyse van de semantische relaties en van de structuur van de tekst maakt, kan het de reproductieve fase van het tolkproces aanzienlijk vergemakkelijken. Goede en overzichtelijke notities spelen hierbij een essentiële rol. Dat geldt vooral voor langere en met veel informatie doorspekte teksten. Ziende mensen maken in dergelijke gevallen meestal gebruik van een kladblok. Voor blinde mensen is deze methode uiteraard ontoegankelijk. Zij kan in bepaalde gevallen door slechtziende mensen worden gebruikt indien hun gezichtsvermogen voldoende is. Blinde tolken moeten daarentegen andere technische hulpmiddelen zoals een notebook of een brailleleesregel gebruiken.

Dolt (2015) stelt met name twee systemen van noteren voor die voor blinde tolken passend zijn: een auditief en een tactiel systeem. Bij beide systemen maakt de blinde of slechtziende tolk gebruik van zijn notebook of ander elektronisch overdraagbaar toestel (een tablet of elektronisch notitieblok). Bij het auditieve systeem schrijft de tolk zijn notities op het toetsenbord en tijdens de reproductiefase luistert hij via de koptelefoon naar de schermlezer. Deze leest de notities meestal per regel. Volgens Figiel (2009) is het optimaal als er relatief weinig tekst op een regel staat. Op die manier kan de tolk de omvang van de informatie die hij in één keer te horen krijgt, gemakkelijk managen. Als het aantal woorden op een regel te groot is, ontstaat het risico dat de tolk niet alles onthoudt en moet de regel opnieuw gelezen worden, hetgeen vertraging voor de tolk veroorzaakt (Figiel, 2009). Bij een te hoog spreektempo van de schermlezer ontstaat natuurlijk ook het risico dat de tolk niet onmiddellijk verstaat wat hij heeft genoteerd. Hij kan de opgeschreven tekst per teken of per woord lezen, maar dat is voor hem dan weer extra tijdverlies.

Om geen pauzes in de reproductiefase te laten vallen, moet de tolk zijn luister- en spreekactiviteit goed coördineren. De tolk kan bij het maken van notities uiteraard geen koptelefoon op hebben, omdat hij naar de originele gesproken tekst moet luisteren. Daarom is het belangrijk dat hij het typen op het toetsenbord goed beheerst. Vooral voor jongere mensen met een ernstige visuele beperking is dat een van de aan te leren basisvaardigheden.

Dolt (2015) beschouwt als een van de voordelen van het auditieve systeem de betere financiële toegankelijkheid in vergelijking met het tactiele systeem. De prijzen van 
brailleleesregels overschrijden immers gemakkelijk de grens van 3000 euro en als de blinde of slechtziende geen vergoeding krijgt, kan de aankoop voor hem problematisch zijn.

Bij het tactiele systeem maakt de blinde tolk gebruik van een brailleleesregel die op zijn notebook aangesloten is. Hij heeft geen koptelefoon nodig en leest zijn aantekeningen met zijn vingers. Aan dit systeem zijn eveneens voor- en nadelen verbonden. Als een van de grootste voordelen beschouwt Dolt (2015) de absentie van de problemen met het verstaan van de notities. De blinde of slechtziende tolk is nu niet op de akoestische vorm van informatie aangewezen. Hij kan dus onder zijn vingers precies datgene voelen wat hij in zijn notities heeft geschreven. Hij kan zijn leestempo naar behoefte zelf regelen (Dolt 2015).

Aan dit systeem zijn echter ook nadelen verbonden. Deze staan in rechtstreeks verband met dat leestempo. De meeste mensen die van jongs af aan blind of slechtziend zijn, kunnen braille relatief goed en snel lezen. Maar er bestaat een grote groep mensen met visuele beperking die met dit schrift problemen hebben of het helemaal niet hebben geleerd. Voor die groep is het tactiele systeem zeker niet passend.

\section{Situatie in Nederland en Vlaanderen}

Wij hebben geprobeerd een klein empirisch onderzoek uit te voeren onder Nederlandse en Vlaamse vertalers en tolken met een visuele beperking. We hebben daartoe een vragenlijst samengesteld en deze via verschillende organisaties van blinde en slechtziende mensen, maar ook via vertalersfora verspreid. Uiteindelijk hebben wij 5 respondenten gevonden die de vragenlijst hebben ingevuld ( 3 uit Vlaanderen en 2 uit Nederland). Wij hebben onze aandacht vooral op de toegankelijkheid van informatiebronnen gericht waarin blinde en slechtziende vertalers en tolken naar mogelijke oplossingen van hun specifieke problemen kunnen zoeken.

Wij hebben onze aandacht gericht op twee centrale vragen:

1. met welke specifieke problemen hebben mensen met een visuele beperking in hun werk te maken?

2. beschikten deze mensen tijdens hun opleiding, dan wel beschikken zij momenteel over toereikende informatie betreffende 1. de oplossing van deze specifieke problemen en

2. ervaringen van andere visueel beperkte vertalers en tolken?

Van onze 5 respondenten zijn 4 nog steeds actief als vertaler of tolk. Eén persoon heeft aangegeven dat de problemen die uit haar beperking voortvloeien, te groot waren en dat zij op zoek is gegaan naar een andere baan. Zij was 8 jaar lang actief als vertaalster. Alle respondenten hebben aangegeven dat zij als vertalers werken of werkten, twee ervan in combinatie met tolkopdrachten. We wijzen er terzijde op dat dit volgens eerder onderzoek overeenkomt met de situatie in andere landen (Homola 2017).

Wat de problemen betreft waarmee deze blinde of slechtziende vertalers en tolken worden geconfronteerd, gaat het hier meestal om dezelfde moeilijkheden die ook door respondenten in andere landen werden aangegeven: slechte toegankelijkheid van een 
aantal CAT-tools, problemen met notitietechniek bij consecutief tolken, teksten in ontoegankelijke vorm (gescande documenten en teksten op papier), ontoegankelijkheid van parallelle teksten / vaktalige bronnen enzovoort. Interessant was het antwoord van een respondent die als literair vertaler werkt:

"Ik gebruik altijd de vertaalwoordenboeken van Van Dale Online. Het gaat dan om de professionele versies, maar die waren een poosje moeilijk toegankelijk, omdat ik doodgewoon geen zoekterm kon ingeven."

Deze respondent heeft vervolgens met de helpdesk van Van Dale contact opgenomen, maar deze heeft geen oplossing aangedragen. Uiteindelijk heeft hij zelf een oplossing gevonden door enkele instellingen te veranderen. Wij hebben tijdens onze studie aan de universiteit zelf ook negatieve ervaringen met de toegankelijkheid van Van Dale woordenboeken (offline versie) gehad en konden deze in feite helemaal niet gebruiken. Dit toont heel duidelijk hoe belangrijk is het om in contact te blijven met andere vertalers of tolken met een visuele beperking. Uit onze enquête blijkt echter dat dit weinig gebeurt: slechts één van de 5 respondenten heeft contact met blinde of slechtziende collega's. Ook tijdens hun studie hebben de ondervraagden slechts algemene ondersteuning voor studenten met een visuele beperking gekregen (digitalisering van studiematerialen, meer tijd om een tentamen te maken, ondersteuning voor de geleidehond...). Zij hebben echter geen informatie gekregen op welke manier zij hun specifieke vertaal- of tolkproblemen kunnen oplossen. Uit onze eigen ervaring kunnen wij vermelden dat het heel moeilijk is om zelfstandig naar mogelijke oplossingen te zoeken. Het is ook efficiënter om tips en trucs onder elkaar uit te wisselen. Hieronder enkele concrete antwoorden:

“Tijdens mijn studie was er iemand aangesteld die een paar uur per week mijn syllabi en ander studiemateriaal hielp scannen, zodat ik ze kon lezen. Andere ondersteuning heb ik nooit gekregen, dus ook niet op het vlak van het vertalen zelf."

"Ik ben met geen enkele slechtziende of blinde persoon meer in contact. De reden hiervoor is dat ik heb gemerkt dat er maar weinig blinden en slechtzienden puur en uitsluitend zakelijke informatie verstrekken (software- en hardwaremogelijkheden bespreken). Het moet vaak ook over persoonlijke visuele omstandigheden gaan, en daar heb ik geen behoefte aan."

"Een internationaal netwerk van blinde of slechtziende vertalers zou wel nuttig kunnen zijn om tips en trucs met elkaar uit te wisselen."

\section{Conclusie}

Wij hopen dat ons onderzoek kan helpen om meer informatie onder blinde en slechtziende vertalers/tolken in Nederland en Vlaanderen te verspreiden. Het is onze ambitie om de uitkomsten met hen te delen en ook de huidige studenten of beginners te helpen toegang te krijgen tot de praktische ervaringen van hun collega's. Er bestaat een inter- 
nationaal netwerk van blinde of slechtziende vertalers en tolken dat bij veel van onze respondenten nog onbekend is, namelijk The round table mailing list. Dankzij deze lijst bestaat de mogelijkheid ervaringen uit te wisseling tussen blinde en slechtziende vertalers en tolken en hun docenten. Het is belangrijk dat alle vertalers en tolken met een visuele beperking op de hoogte gesteld worden van het bestaan van deze lijst.

Wij zijn ons ervan bewust dat de relevantie van ons onderzoek in Nederland en Vlaanderen relatief beperkt is. Het aantal respondenten is waarschijnlijk te klein om de situatie in de kaart te brengen, maar het is een goede basis voor verder onderzoek. Er zijn zeker in deze twee landen nog meer mensen met een visuele beperking die als vertaler of tolk actief zijn en met wie wij nog geen contact hebben kunnen opnemen. En er is zeker nog een andere belangrijke doelgroep van ons onderzoek: docenten vertaal- en tolkwetenschap die aan blinde of slechtziende studenten doceren en die soms helemaal niet weten op welke manier zij deze studenten verder kunnen helpen.

\section{BIBLIOGRAFIE}

CRACIUNESCU, OLIVIA (2004). "Machine Translation and Computer-Assisted Translation: a New Way of Translating?", in: Translation Journal, nr. 8. URL: http://translationjournal.net/journal/29 computers.htm [25-03-2017].

DOLT, DANIELA (2015). Die Notizentechnik blinder Dolmetscherinnen beim Konsekutivdolmetschen (masterscriptie). Graz: Karl-Franzens-Universität.

FIGIEL, WOJTECH (2009). Note-taking in consecutive interpreting for the blind (masterscriptie). Warschau: Universiteit van Warschau.

HAGEMANN, SUSANNE (2016). "Teaching Translation to Mixed Groups of Blind and Sighted Students", in: The Journal of Translator Education and Translation Studies, $\mathrm{nr}$ 1,

URL: http://www.tetsjournal.org/TETS/2016/01_01/Paper_7_1_1.pdf [26-02-2017].

HOMOLA, MICHAL (2017). Taaltechnologieën en hulpmiddelen voor blinde/slechtziende vertalers en tolken. Bratislava: Univerzita Komenského v Bratislave.

JONES, RODERICK (2002). Conference Interpreting Explained. Manchester: St. Jerome Publishing.

MENDELOVÁ, ELENA (2013). Vzdelávanie nevidiacich s použitím moderných technológií. Bratislava: Centrum podpory študentov so špecifickými potrebami.

RODRÍGUEZ VÁZQUEZ, SILVIA \& FIORENZA MILETO (2016). “On the Lookout for Accessible Translation Aids: Current Scenario And New Horizons for Blind Translation Students and Professionals", in: The Journal of Translator Education and Translation Studies, nr. 2.

\section{ZRAKOVĚ POSTIŽENÍ PŘEKLADATELÉ A TLUMOČNÍCI SPECIFICKÉ PROBLÉMY A MOŽNÁ ŘEŠENÍ}

Zrakově postižení překladatelé a tlumočníci se musí při práci vyrovnávat s různými specifickými problémy. Pokrok moderních technologií zjednodušil jejich přístup $\mathrm{k}$ informačním zdrojům, na druhé straně však vytvořil nové překážky, které ztěžují jejich postavení na trhu překladatelských a tlumočnických služeb. V magisterské práci jsme analyzovali problémy zrakově postižených překladatelů a tlumočníků, zejména na základě jejich vlastních zkušeností. Vypracovali jsme dotazník, který vyplnili nevidomí a slabozrací překladatelé a tlumočníci z celého světa. $V$ tomto článku chceme představit výsledky tohoto výzkumu. Dále se snažíme zmapovat situaci v nizozemské jazykové oblasti a porovnat ji s celosvětovými výsledky. V Nizozemsku a Vlámsku jsme našli několik zrakově postižených překla- 
datelů a tlumočníků a požádali jsme je, aby vyplnili rozšířený dotazník. Počet našich respondentů sice nebyl dostatečně vysoký, aby bylo možné vyvodit obecné závěry, je nicméně možné vidět určité paralely nebo rozdíly.

\section{Michal Homola}

Univerzita Komenského v Bratislave

E-mail:michal.homola55@gmail.com 